\title{
Preoperative Peak Oxygen Uptake in Lung Cancer Subjects With Neoadjuvant Chemotherapy: A Cross-Sectional Study
}

\author{
Isabelle Fresard MD, Marc Licker MD, Dan Adler MD, Alban Lovis MD, John Robert MD, \\ Wolfram Karenovics MD, John Diaper RN, Jean-Paul Janssens MD, Frederic Triponez MD, \\ Frederic Lador MD, Thierry Rochat MD, Vicente Espinosa MD, Chetna Bhatia, Bengt Kayser MD, \\ and Pierre-Olivier Bridevaux MD MSc
}

\begin{abstract}
BACKGROUND: In non-small-cell lung cancer patients, high peak oxygen uptake (peak $\dot{\mathrm{V}}_{\mathrm{O}_{2}}$ ) predicts lower rates of postoperative complications and better long-term survival. Neoadjuvant chemotherapy (NAC) may negatively impact peak $\dot{\mathbf{V}}_{\text {O. }}$. METHODS: Cardiopulmonary exercise testing (CPET) was performed in 34 consecutive stage IIIA/IIIB non-small-cell lung cancer subjects scheduled for elective lung surgery. Using multivariate linear regression adjusted for potential confounders, we compared CPET results in subjects receiving or not receiving NAC (NAC+, $n=19$; NAC,$- n=15)$. RESULTS: Adjusted peak $\dot{\mathbf{V}}_{\mathrm{O}_{2}}$ was lower in NAC + compared with NACsubjects $(-5.3 \mathrm{~mL} / \mathrm{min} / \mathrm{kg}[95 \% \mathrm{CI}-8.3$ to -2.2$], P=.01)$. Likewise, oxygen pulse, maximal work load, and ventilatory threshold were also lower in NAC+ subjects, whereas peak heart rate and breathing reserve were similar. NAC + subjects presented lower values of diffusion capacity for carbon monoxide $\left(\mathrm{D}_{\mathrm{LCO}}\right)(P=.035)$ and hemoglobin concentrations $(P<.001)$. $\mathrm{D}_{\mathrm{LCO}}$ was strongly correlated with peak $\dot{\mathrm{V}}_{\mathrm{O}_{2}}\left(\mathrm{r}^{2}=\mathbf{0 . 5 6}\right)$. Adjustment for $\mathrm{D}_{\mathrm{LCO}}$ reduced the effect of NAC on peak $\dot{\mathrm{V}}_{\mathrm{O}_{2}}$ without suppressing it. CONCLUSIONS: NAC was associated with lower preoperative peak $\dot{\mathrm{V}}_{\mathrm{O}_{2}}$ in subjects with non-small-cell lung cancer. This lower aerobic fitness may result from NAC-induced reduction in pulmonary gas exchange or heart toxicity. Since lower fitness is linked to poorer outcome, the decision for NAC may have to be balanced with its possible toxicity. Key words: chemotherapy, peak oxygen uptake, cardio-pulmonary exercise tests, lung cancer, lung surgery, training, post operative complications. [Respir Care 2016;61(8):1059-1066. (c) 2016 Daedalus Enterprises]
\end{abstract}

\section{Introduction}

Patients with non-small-cell lung cancer generally have limited exercise capacity. ${ }^{1}$ Aerobic exercise capacity is a key variable for the decision to perform tumor resection. This process involves oxygen transport and delivery by the pulmonary and cardiovascular systems and oxygen consumption by the skeletal muscles. ${ }^{2}$ Peak oxygen uptake (peak $\dot{\mathrm{V}}_{\mathrm{O}_{2}}$ ), as determined during cardiopulmonary exer-

racic and Endocrine Surgery, Geneva Faculty of Medicine, University Hospitals of Geneva, Geneva, Switzerland. Dr Kayser is affiliated with the Institute of Sport Sciences and Department of Physiology, University of Lausanne, Lausanne, Switzerland and Faculty of Medicine, University of Geneva, Geneva, Switzerland.

This work was supported by the University of Geneva, the University Hospitals of Geneva, and the Ligue Genevoise contre le Cancer. The authors have disclosed no conflicts of interest.

Supplementary material related to this paper is available at http:// www.rcjournal.com. 
cise testing (CPET), is the reference method to evaluate exercise capacity and predicts early postoperative complications as well as long-term outcome. ${ }^{3-6}$ Besides aging, comorbidities such as COPD, diabetes mellitus, hypertension, peripheral artery disease, and heart failure are highly prevalent in these patients and may all limit aerobic exercise capacity. ${ }^{7}$ Moreover, sedentary behavior and the inflammatory component associated with cancer contribute to muscle wasting and decreased peripheral aerobic metabolic capacity. Finally, there can be deleterious effects of surgery, radiotherapy, and chemotherapy. ${ }^{1}$

Chemotherapeutic agents can affect the cardiovascular system and induce anemia, both impeding cardiovascular oxygen transport. ${ }^{8}$ Platinum-based chemotherapy may affect the pulmonary system, worsening pulmonary oxygen uptake. ${ }^{8}$ The effects of other classes of chemotherapeutic agents and the effects of chemotherapy in general on other components of oxygen delivery and consumption are still poorly explored. ${ }^{9}$ Despite such serious adverse effects, survival is improved with preoperative neoadjuvant chemotherapy (NAC) followed by surgery, compared with surgery alone. ${ }^{10-12}$ By reducing the tumor burden and downgrading the tumor stage, NAC facilitates surgical resection and may improve long-term outcome by eradicating micrometastases. But NAC may be a double-edged sword. There is emerging evidence that NAC may decrease physical fitness by affecting oxygen transport system components, although it is still unclear which NAC toxicity-related effects result in lowered aerobic capacity. ${ }^{13}$

To address this point, we compared preoperative CPETderived parameters in a cohort of non-small-cell lung cancer subjects scheduled for curative lung resection and receiving or not receiving NAC. We hypothesized that subjects receiving NAC would have lower aerobic exercise capacity compared with subjects not treated with NAC.

\section{Methods}

\section{Study Design and Setting}

This prospective study took place over a period of 49 months, from January 2011 to February 2014, as part of an ongoing randomized controlled trial comparing the effect of short-term preoperative exercise training versus usual care in subjects with operable non-small-cell lung cancer. ${ }^{14}$ All subjects were recruited in the pulmonary di-

Correspondence: Isabelle Fresard, University Hospitals of Geneva, Division of Pulmonary Medicine, Hopital de La Tour, Av J.-D. Maillard 3, 1217 Meyrin, Switzerland. E-mail: isabelle.fresard@latour.ch.

DOI: $10.4187 /$ respcare.04299

\section{QUICK LOOK}

\section{Current knowledge}

In patients with non-small-cell lung cancer, the postoperative complication rate is associated with low peak oxygen uptake. Neoadjuvant chemotherapy has been shown to be effective in improving survival when compared with surgery alone in selected patients. However, toxicity of chemotherapeutic agents may affect heart and lung function beyond anemia, thus reducing peak oxygen uptake.

\section{What this paper contributes to our knowledge}

Neoadjuvant chemotherapy was associated with significantly lower preoperative oxygen uptake in subjects with non-small-cell lung cancer. This lower aerobic fitness may result from chemotherapy-induced reduction in diffusion capacity and heart or skeletal muscle toxicity.

visions of 3 tertiary care centers located in the Frenchspeaking part of Switzerland (University Hospitals of Geneva, University Hospital of Lausanne, and Hôpital du Valais, Sion). A cross-sectional analysis was carried out to assess preoperative exercise capacity (as measured by CPET) in non-small-cell lung cancer subjects with or without NAC scheduled for elective curative lung resection.

\section{Participants}

We included all subjects $>18$ y old with non-small-cell lung cancer IIIA and IIIB, documented by CT scan, positron emission tomography-CT, and pathological confirmation and judged eligible for tumor resection (open thoracotomy or video-assisted thoracoscopy), with or without NAC. The institutional research ethics board approved the study and informed written consent was obtained from each subject. Institutional review board approval (Protocol 09-263) was obtained from the University Hospitals of Geneva on August 10, 2010.

Based on preoperative investigations, subjects were staged according to the guidelines of the American Joint Committee on Cancer. ${ }^{15}$ Decisions to offer NAC were made by a multidisciplinary tumor board, based on guidelines, clinical judgment, and subjects' preferences. Exclusion criteria consisted of contraindications to perform CPET (uncontrolled heart disease, severe pulmonary hypertension) or functional limitations related to joint or psychiatric disease that precluded CPET. 


\section{Peak $\dot{V}_{\mathrm{O}_{2}}$ Uptake in Lung Cancer Subjects Receiving Chemotherapy}

\section{Outcomes, Exposure Variables, and Potential Confounders}

The main outcome variable was peak $\dot{\mathrm{V}}_{\mathrm{O}_{2}}$ obtained from CPET. Secondary outcomes were other CPET results (maximal work load, ventilatory threshold, ventilatory equivalents $\left[\dot{\mathrm{V}}_{\mathrm{E}} / \dot{\mathrm{V}}_{\mathrm{O}_{2}}\right.$ and $\dot{\mathrm{V}}_{\mathrm{E}} / \dot{\mathrm{V}}_{\mathrm{CO}_{2}}$ ], breathing reserve [estimated], peak heart rate, and oxygen pulse $\left[\dot{\mathrm{V}}_{\mathrm{O}_{2}} /\right.$ heart rate]). Data were collected preoperatively after a median of $3.1 \pm 0.5$ cycles of NAC. In accordance with international guidelines, NAC regimens consisted of platinum-based doublet chemotherapy (supplementary Table 1; see the supplementary materials at http://www.rcjournal.com). ${ }^{16,17}$

Nineteen subjects with stage IIIA and IIIB non-smallcell lung cancer who received NAC as part of a multimodal treatment were considered as exposed $(\mathrm{NAC}+)$. Subjects with non-small-cell lung cancer stage IIIA and IIIB who did not receive NAC $(n=15)$ were considered as the control group (NAC-). Subjects with stage I to IIB operable lung cancer who did not receive NAC $(n=113)$ were used as additional controls in a sensitivity analysis. The following potential confounders or precision variables were taken into account in the statistical analysis: age, sex, weight, height, self-reported comorbidities (cardiovascular disease, hypertension), pulmonary function $\left(\mathrm{FEV}_{1}\right.$, carbon monoxide diffusion capacity $\left.\left[\mathrm{D}_{\mathrm{LCO}}\right]\right)$, venous blood hemoglobin concentration, and $\mathrm{N}$-terminal prohormone of brain natriuretic peptide (NT-proBNP).

\section{Pulmonary Function and CPET Procedures}

All subjects performed pulmonary function testing according to American Thoracic Society/European Respiratory Society recommendations with measurement of postbronchodilator $\mathrm{FEV}_{1}$ and carbon monoxide diffusion capacity $\left(\mathrm{D}_{\mathrm{LCO}}\right.$ adjusted for hemoglobin according to the following formula: $\mathrm{D}_{\mathrm{LCO}}$ predicted for $\mathrm{Hb}=\mathrm{D}_{\mathrm{LCO}}$ predicted $\times(1.7 \mathrm{Hb} / 10.22+\mathrm{Hb}) .{ }^{18,19}$ Symptom-limited CPET was performed on a cycle ergometer (Vmax Encore, SensorMedics, San Diego, California) with a maximal incremental work load protocol (10-15-W increments every minute, after a 3-min warm-up at $25 \mathrm{~W}$ ), recording work load, breath-by-breath gas exchange, electrocardiogram, pulse oximetry, and noninvasive blood pressure. The flow meter was calibrated with a 3-L syringe, and the gas analyzers were calibrated with certified calibration gas mixtures before each test. The subjects exercised until exhaustion or until reaching criteria for exercise termination according to the American Thoracic Society/American College of Chest Physicians statement. ${ }^{20}$ CPET was considered objectively maximal if the respiratory quotient was $>1.2$ or peak heart rate was $>80 \%$ predicted. ${ }^{21}$ It was considered as subjectively maximal if the subject perceived breathlessness of 9-10 on a $0-10$ Borg scale. Ventilatory threshold was determined with the ventilatory equivalent method and the V-slope method. ${ }^{20}$ Breathing reserve was estimated with the formula: (measured maximal ventilation [MVV] predicted - MVV)/MVV predicted. ${ }^{22}$

\section{Statistical Analysis}

Categorical and continuous variables were compared between the NAC + and NAC - groups with parametric Student test or chi-square test. Univariate and multivariate linear regressions were performed with CPET parameters as dependent variables and NAC exposure (dichotomous) as the main independent variable. Potential confounders were added hierarchically into the models.

Model 1 was unadjusted. Model 2 was adjusted for anthropometric variables (age, sex, height, and weight). Model 3 controlled for comorbidities (cardiovascular disease, hypertension, and $\mathrm{FEV}_{1}$ as proxy of chronic obstructive pulmonary disease). Model 4 was further adjusted for hemoglobin, whereas Model 5 was further adjusted for $\mathrm{D}_{\text {LCO }}$.

A supplementary analysis including as comparators all NAC - lung cancer subjects (stages I to III instead of stage III only) was performed. Statistical analyses were performed with STATA IC 11 (StataCorp, College Station, Texas).

\section{Results}

Between January 2011 and February 2014, we enrolled 34 non-small-cell lung cancer subjects from the University Hospitals of Geneva $(n=24)$ and Lausanne $(n=5)$ and the Valais Hospital $(n=5)$. Subjects' characteristics are shown in Table 1. NAC + subjects had either stage IIIA non-small-cell lung cancer $(n=13)$ or stage IIIB nonsmall-cell lung cancer $(n=6)$. Overall, NAC + subjects tended to be younger and had lower hemoglobin and $\mathrm{D}_{\mathrm{LCO}}$ but similar percent-of-predicted $\mathrm{FEV}_{1}$ and NT-proBNP compared with those without NAC.

Chemotherapeutic regimens were platinum-based for all subjects (cisplatin $n=16$; carboplatin $n=3$ ) combined with docetaxel $(n=16)$, paclitaxel $(n=1)$, gemcitabin $(n=1)$, or vinorelbine $(n=1)$. Two subjects received a combined treatment of cisplatin-docetaxel and cetuximab. The median number of cycles was 3 (range 1-4). Mean time between first cycle of NAC and CPET was $76 \mathrm{~d}(95 \%$ CI 62-90).

Table 2 compares the main CPET results between nonsmall-cell lung cancer IIIA and IIIB subjects with and without NAC. Peak $\dot{\mathrm{V}}_{\mathrm{O}_{2}}$, ventilatory threshold, and oxygen pulse at peak were lower in the NAC + group as compared with control groups. Maximal heart rate reserve at peak (expressed in percent of maximal predicted heart rate) was similar in both groups $(12 \% \pm 14 \%$ in NAC $-; 11 \% \pm$ $11 \%$ in $\mathrm{NAC}+$ ). Table 3 displays the differences in CPET 
Table 1. Subjects' Baseline Characteristics

\begin{tabular}{|c|c|c|c|}
\hline Characteristics & $\begin{array}{c}\text { NAC }+, \text { Stages } \\
\text { IIIA/IIIB } \\
(n=19)\end{array}$ & $\begin{array}{c}\text { NAC }-, \text { Stages } \\
\text { IIIA/IIIB } \\
(n=15)\end{array}$ & $P$ \\
\hline Age, mean $\pm \mathrm{SD} y$ & $59 \pm 12$ & $66 \pm 14$ & .12 \\
\hline Male sex, $\%$ & $12(63.2)$ & $9(60.0)$ & $>.99$ \\
\hline Height, mean $\pm \mathrm{SD} \mathrm{cm}$ & $172 \pm 8$ & $170 \pm 7$ & .31 \\
\hline Weight, mean $\pm \mathrm{SD} \mathrm{kg}$ & $75 \pm 15$ & $69(13)$ & .32 \\
\hline Hemoglobin, mean $\pm \mathrm{SD} g / \mathrm{dL}$ & $11.3 \pm 1.5$ & $13.5(1.9)$ & $<.001$ \\
\hline \multicolumn{4}{|l|}{ Pulmonary function, mean $\pm \mathrm{SD}$} \\
\hline $\mathrm{FEV}_{1}$, mean $\pm \mathrm{SD} \%$ predicted & $85 \pm 17$ & $89 \pm 20$ & .61 \\
\hline $\mathrm{D}_{\mathrm{LCO}}$, mean $\pm \mathrm{SD} \%$ predicted & $60 \pm 19$ & $75 \pm 18$ & .035 \\
\hline NT-proBNP, mean \pm SD pg/mL & $47 \pm 38$ & $66 \pm 63$ & .31 \\
\hline \multicolumn{4}{|l|}{ Comorbidities, $n(\%)$} \\
\hline Cardiovascular disease & $4(21.1)$ & $3(20.0)$ & $>.99$ \\
\hline Hypertension & $6(31.6)$ & $4(26.7)$ & $>.99$ \\
\hline COPD & $6(31.6)$ & $7(46.7)$ & .48 \\
\hline Depression & $4(22.2)$ & $3(21.4)$ & $>.99$ \\
\hline \multicolumn{4}{|l|}{ Preoperative staging, $n(\%)$} \\
\hline IIIA & $13(68.4)$ & $14(93.3)$ & \\
\hline IIIB & $6(31.6)$ & $1(6.7)$ & \\
\hline
\end{tabular}

Table 2. Cardiopulmonary Exercise Test Results

\begin{tabular}{|c|c|c|c|}
\hline Parameters & $\begin{array}{c}\text { NAC+, Stages } \\
\text { IIIA/IIIB } \\
(n=19)\end{array}$ & $\begin{array}{c}\text { NAC- }, \text { Stages } \\
\text { IIIA/IIIB } \\
(n=15)\end{array}$ & $P$ \\
\hline Peak $\dot{\mathrm{V}}_{\mathrm{O}_{2}}, \mathrm{~mL} / \mathrm{min}$ & $1,174 \pm 306$ & $1,446 \pm 596$ & .09 \\
\hline Peak $\dot{\mathrm{V}}_{\mathrm{O}_{2}}, \mathrm{~mL} / \mathrm{min} / \mathrm{kg}$ & $16.4 \pm 3.6$ & $20.5 \pm 6.5$ & .02 \\
\hline Peak power, $\mathrm{W}$ & $89.0 \pm 27.8$ & $97.3 \pm 51.7$ & .5 \\
\hline $\begin{array}{l}\text { Ventilatory threshold, } \% \\
\text { predicted peak } \dot{\mathrm{V}}_{\mathrm{O}_{2}}(\mathrm{SD})\end{array}$ & $39.7 \pm 11.1$ & $51.3 \pm 14.4$ & .02 \\
\hline Peak $\dot{V}_{E}, L / m i n$ & $60.3 \pm 16.7$ & $63.8 \pm 23.5$ & .65 \\
\hline$\dot{\mathrm{V}}_{\mathrm{E}} / \dot{\mathrm{V}}_{\mathrm{O}_{2}}$ at ventilatory threshold & $36.7 \pm 5.9$ & $36.8 \pm 6.0$ &. \\
\hline$\dot{\mathrm{V}}_{\mathrm{E}} / \dot{\mathrm{V}}_{\mathrm{CO}_{2}}$ at ventilatory threshold & $37.21 \pm 5.2$ & $37.3 \pm 4.9$ & .93 \\
\hline $\mathrm{S}_{\mathrm{pO}_{2}}, \%$ at peak & $96.1 \pm 1.0$ & $95.4 \pm 1.5$ & .1 \\
\hline Breathing reserve, $\%$ at peak & $38.4 \pm 20.7$ & $32.5 \pm 16.0$ & .40 \\
\hline Peak heart rate, beats/min & $143.6 \pm 22.4$ & $135.2 \pm 23.1$ & .29 \\
\hline $\begin{array}{l}\text { Heart rate reserve, beats/min } \\
\text { at peak }\end{array}$ & $17.5 \pm 16.8$ & $18.8 \pm 21.2$ & .8 \\
\hline $\begin{array}{l}\text { Oxygen pulse, } \mathrm{mL} / \text { beat at } \\
\text { peak }\end{array}$ & $8.3 \pm 2.3$ & $10.6 \pm 3.3$ & .0 \\
\hline \multicolumn{4}{|c|}{$\begin{array}{l}\text { Data are means } \pm \mathrm{SD} \\
\mathrm{NAC}=\text { neoadjuvant chemotherapy } \\
\dot{\mathrm{V}}_{\mathrm{O}_{2}}=\text { oxygen consumption } \\
\dot{\mathrm{V}}_{\mathrm{E}}=\text { minute ventilation } \\
\dot{\mathrm{V}}_{\mathrm{E}} / \dot{\mathrm{V}}_{\mathrm{O}_{2}} \text { and } \dot{\mathrm{V}}_{\mathrm{E}} / \mathrm{V}_{\mathrm{CO}_{2}}=\text { ventilatory equivalents at ventilatory threshold }\end{array}$} \\
\hline
\end{tabular}

parameters in subjects with versus without NAC as obtained from the multivariate analysis.

Peak $\dot{\mathrm{V}}_{\mathrm{O}_{2}}$ was significantly lower in NAC + subjects in multivariate linear regression models when compared with NAC - subjects. Lower peak $\dot{\mathrm{V}}_{\mathrm{O}_{2}}$ associated with NAC was also found in Models 2 and 3 controlling for anthropometric variables and comorbidities, respectively $(-5.3 \mathrm{~mL} / \mathrm{min} / \mathrm{kg}(95 \% \mathrm{CI}-8.3$ to -2.2$), P=.001$ and
$-5.2 \mathrm{~mL} / \mathrm{min} / \mathrm{kg}(95 \% \mathrm{CI}-8.2$ to -2.3$), P=.001)$. The impact on peak $\dot{\mathrm{V}}_{\mathrm{O}_{2}}$ was less pronounced in Models 4 and 5 , which were additionally adjusted for hemoglobin and $\mathrm{D}_{\mathrm{LCO}}$, respectively, suggesting a role for these 2 variables in exercise capacity. Maximal work load was lower in the $\mathrm{NAC}+$ subjects in Models 2 and 3, and ventilatory threshold was lower in Models 1-3.

The relations between peak $\dot{\mathrm{V}}_{\mathrm{O}_{2}}$ and $\mathrm{D}_{\mathrm{LCO}}$, against peak heart rate, are depicted in supplementary Figures 1 and 2 . We observed no statistically significant differences between groups for $\dot{\mathrm{V}}_{\mathrm{E}} / \dot{\mathrm{V}}_{\mathrm{O}_{2}}, \dot{\mathrm{V}}_{\mathrm{E}} / \dot{\mathrm{V}}_{\mathrm{CO}_{2}}$, breathing reserve, and heart rate. By contrast, the slope of the $\dot{\mathrm{V}}_{\mathrm{O}_{2}}$ /heart rate relationship was flatter in NAC+ subjects (peak $\left.\dot{\mathrm{V}}_{\mathrm{O}_{2}}=9.3 \pm 0.5, \mathrm{r}^{2}=0.09, P=.20\right)$ compared with the $\mathrm{NAC}-$ subjects (peak $\dot{\mathrm{V}}_{\mathrm{O}_{2}}=-1.1 \pm 0.16, \mathrm{r}^{2}=0.31$, $P=$.035) (supplementary Fig. 2). Supplementary Figures 3 and 4 show similar relations between $\mathrm{V}_{\mathrm{O}_{2}}$ and $\mathrm{D}_{\mathrm{LCO}}$ against heart rate, based on the sensitivity analysis, including all cancer subjects as controls. We also noted a lower oxygen pulse at peak exercise in subjects with NAC in all multivariate models (see Table 3 ).

\section{Discussion}

As hypothesized, we found that subjects with non-smallcell lung cancer stage IIIA and IIIB who received NAC had a $25.8 \%$ lower preoperative peak $\dot{\mathrm{V}}_{\mathrm{O}_{2}}(-5.3 \mathrm{~mL} / \mathrm{min} / \mathrm{kg})$ compared with those not receiving NAC, after adjustment for anthropometric variables, comorbidities, and $\mathrm{FEV}_{1}$. $\mathrm{NAC}+$ subjects also reached a lower maximal work load, had a lower oxygen pulse at peak exercise, and had a decreased ventilatory threshold, whereas breathing reserve, heart rate at peak exercise, and ventilatory equivalents at ventilatory threshold were similar in both groups. $\mathrm{FEV}_{1}$ and NT-proBNP were comparable in NAC+ and NACsubjects, but $\mathrm{D}_{\mathrm{LCO}}$ and hemoglobin level were lower in the $\mathrm{NAC}+$ group. $\mathrm{D}_{\mathrm{LCO}}$ and, to a somewhat lesser extent, hemoglobin were associated with exercise capacity. The finding of a flatter $\dot{\mathrm{V}}_{\mathrm{O}_{2}}$ /heart rate regression slope and a lower peak oxygen pulse in the NAC + group compared with the control groups suggests a cardiac component to their lower aerobic capacity (see Table 2 and supplementary Fig. 2).

Three different mechanisms may explain the lower aerobic capacity in the non-small-cell lung cancer subjects receiving NAC. First the reduction in $\mathrm{D}_{\mathrm{LCO}}$, although nonspecific, suggests impaired gas exchange limiting exercise capacity. Second, reduced blood hemoglobin concentration limits oxygen carrying capacity. Third, the data presented are consistent with a lower cardiac stroke volume and therefore cardiac output, limiting oxygen delivery. We cannot exclude a peripheral component involved in the decrease in peak $\dot{\mathrm{V}}_{\mathrm{O}_{2}}$, such as muscle (mitochondrial) 


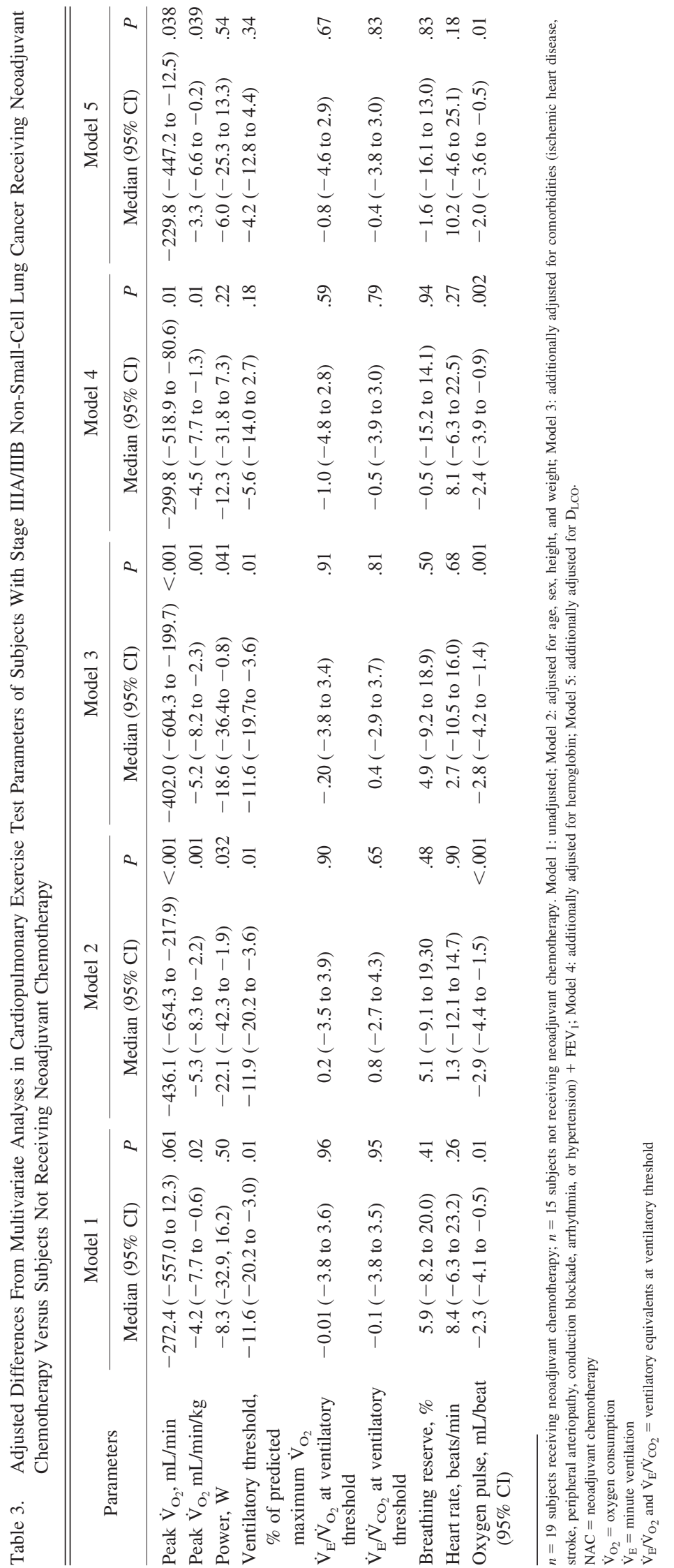


toxicity of NAC, but we have no data to support this hypothesis.

\section{Diffusion Capacity}

In our study, $\mathrm{D}_{\mathrm{LCO}}$ was 15 points lower in $\mathrm{NAC}+$ compared with NAC- subjects. $\mathrm{D}_{\mathrm{LCO}}$ is an important determinant of aerobic capacity. For example, in COPD patients, $\mathrm{D}_{\mathrm{LCO}}$ is a strong predictor of peak $\dot{\mathrm{V}}_{\mathrm{O}_{2}}{ }^{23}$ A decrease in $\mathrm{D}_{\mathrm{LCO}}$ is a common finding when performing lung function tests during or after chemotherapy. Lakoski et $\mathrm{al}^{9}$ reviewed the effects of chemotherapeutic agents on components of oxygen transport and suggested that platinumbased chemotherapy impacts its pulmonary component, presumably by diminishing diffusion capacity. Pulmonary toxicity was also reported for taxanes and gemcitabine. Kreuter et $\mathrm{al}^{24}$ assessed lung function after 2 different adjuvant chemotherapeutic regimens for early stage nonsmall-cell lung cancer and found a decline of $\mathrm{D}_{\mathrm{LCO}}$ after a cisplatin-vinorelbine regimen $(-8 \%)$ but not after cisplatin-pemetrexed $(-0.4 \%)$. This is consistent with the results of Rivera et $\mathrm{al}^{25}$ who found an $8 \% \mathrm{D}_{\mathrm{LCO}}$ decline after 3 courses of gemcitabine plus carboplatin, cisplatin, or paclitaxel for stage I and II non-small-cell lung cancer. Leo et $\mathrm{al}^{26}$ compared pre- and post-NAC ( 3 courses of cisplatin-gemcitabine) lung function in 30 subjects with stage IIIA-N2 non-small-cell lung cancer. They found an $11 \% \mathrm{D}_{\mathrm{LCO}}$ reduction after chemotherapy. Takeda et $\mathrm{al}^{27}$ found a $21 \%$ reduction in $\mathrm{D}_{\mathrm{LCO}}$ after induction therapy (chemotherapy alone or chemo-radiotherapy) for stage IIB (Pancoast), IIIA, and IIIB non-small-cell lung cancer. Importantly, $\mathrm{D}_{\mathrm{LCO}}$ was an independent predictor of postoperative pulmonary morbidity. ${ }^{28}$

\section{Oxygen Transport}

From the Fick principle, we know that a reduction in blood hemoglobin content will result in a reduction of peak $\dot{\mathrm{V}}_{\mathrm{O}_{2}}{ }^{29}$ Virtually all chemotherapeutic agents may cause anemia through different pathways (deficient production or destruction of red blood cells, excessive blood loss). Anemia during chemotherapy occurs in $30-100 \%$ of patients. ${ }^{30} \mathrm{~A}$ correlation between hemoglobin levels and peak $\dot{\mathrm{V}}_{\mathrm{O}_{2}}$ reduction was described for women receiving adjuvant chemotherapy for breast cancer. ${ }^{31}$ In our study, adjustment for hemoglobin marginally altered the association between NAC and peak $\dot{\mathrm{V}}_{\mathrm{O}_{2}}$, suggesting that the effect of NAC on peak $\dot{\mathrm{V}}_{\mathrm{O}_{2}}$ in our cohort was mainly mediated by other mechanisms.

\section{Cardiotoxicity}

Several chemotherapeutic agents are cardiotoxic. Anthracylines, trastuzumab, and tyrosine kinase inhibitors are frequently associated with left ventricular dysfunction and impairment in cardiovascular autonomic regulation. ${ }^{32,33}$ Antimicrotubule agents such as paclitaxel are reported to induce various cardiac problems, including bradyarrhythmias, atrioventricular conduction blocks, bundle branch blocks, and cardiac ischemia. Our observation of a flattening of the peak $\dot{\mathrm{V}}_{\mathrm{O}_{2}}$ /heart rate relationship and a lower peak oxygen pulse is compatible with a cardio-toxic component of NAC, although simple deconditioning cannot be excluded.

\section{Lung Volumes}

In our study, NAC was not associated with lower lung volumes. This is in line with published literature showing similar total lung capacity, FVC, and $\mathrm{FEV}_{1}$ in subjects exposed to different combinations of chemotherapeutic agents, mainly platinum-based doublet. Kreuter et al ${ }^{24}$ and Rivera et al ${ }^{25}$ reported no decrease of $\mathrm{FEV}_{1}, \mathrm{FVC}$, or total lung capacity. Two studies even reported an improvement in lung volumes after NAC. ${ }^{24,26}$

\section{Limitations}

Several limitations should be taken into account when interpreting our results. First, direct toxicity on pulmonary, circulatory, neural, and muscular components cannot be distinguished from the indirect effects of chemotherapeutic agents such as deconditioning or changes in body weight and composition due to physical inactivity. Second, our study was not designed to determine the relationship between NAC and short- or long-term surgical therapeutic outcome, precluding any conclusions on this specific point. Finally, we did not perform CPET before starting NAC to measure longitudinally its impact on CPET results. Observations were made on the basis of the CPET post-NAC only. Our cross-sectional design thus limits any strong conclusions on causality, although collectively, the literature convincingly suggests such a causal relationship. We find that the potential limitation of peak $\dot{\mathrm{V}}_{\mathrm{O}_{2}}$ after NAC should nevertheless be taken into account in the still ongoing debate of choosing preoperative versus postoperative chemotherapy. Research should specifically address the effects of NAC on postoperative complications and the role of CPET as a risk-stratifying tool.

\section{Implications for Clinical Decision and Research}

Clinicians in charge of multimodal therapy in non-smallcell lung cancer should carefully weigh the risks against the potential benefits of NAC, since it may contribute to decreasing fitness level and thus impact the short- and long-term outcome of primary tumor resection. Patients should be advised to maintain or even increase their level 


\section{Peak $\dot{V}_{\mathrm{O}_{2}}$ Uptake in Lung Cancer Subjects Receiving Chemotherapy}

of fitness when started on NAC. In this perspective, randomized controlled trials suggests benefits from preoperative high intensity training in subjects with non-small-cell lung cancer bring new therapeutic modalities when addressing surgical risk for lung cancer patients. ${ }^{34,35}$ However, exercise training in patients with NAC may represent a significant challenge.

\section{Conclusion}

NAC was associated with a reduced exercise capacity in potentially resectable stage IIIA and IIIB non-small-cell lung cancer subjects. Impaired gas exchange (reduced $\mathrm{D}_{\mathrm{LCO}}$ ), decreased oxygen transport (anemia), cardiotoxicity, and physical deconditioning are plausible mechanisms involved. Because peak $\dot{\mathrm{V}}_{\mathrm{O}_{2}}$ is a major predictive factor for peri- and postoperative complications and of short-term survival, NAC could potentially influence these outcomes. Randomized controlled trials should be conducted to assess whether the reduced exercise capacity related to NAC influences outcome and whether it could be improved by concurrent physical rehabilitation.

\section{ACKNOWLEDGMENTS}

We thank Elise Dupuis for statistical assistance.

\section{REFERENCES}

1. Jones LW, Eves ND, Haykowsky M, Freedland SJ, Mackey JR. Exercise intolerance in cancer and the role of exercise therapy to reverse dysfunction. Lancet Oncol 2009;10(6):598-605.

2. Wagner PD. Why doesn't exercise grow the lungs when other factors do? Exerc Sport Sci Rev 2005;33(1):3-8.

3. Brunelli A, Pompili C, Salati M, Refai M, Berardi R, Mazzanti P, Tiberi M. Preoperative maximum oxygen consumption is associated with prognosis after pulmonary resection in stage I non-small cell lung cancer. Ann Thorac Surg 2014;98(1):238-242.

4. Brunelli A, Charloux A, Bolliger CT, Rocco G, Sculier JP, Varela G, et al. ERS/ESTS clinical guidelines on fitness for radical therapy in lung cancer patients (surgery and chemo-radiotherapy). Eur Respir J 2009;34(1):17-41

5. Licker M, Schnyder JM, Frey JG, Diaper J, Cartier V, Inan C, et al. Impact of aerobic exercise capacity and procedure-related factors in lung cancer surgery. Eur Respir J 2011;37(5):1189-1198.

6. Loewen GM, Watson D, Kohman L, Herndon JE 2nd, Shennib H, Kernstine K, et al. Preoperative exercise VO2 measurement for lung resection candidates: results of Cancer and Leukemia Group B Protocol 9238. J Thorac Oncol 2007;2(7):619-25.

7. Moro-Sibilot D, Aubert A, Diab S, Lantuejoul S, Fourneret P, Brambilla E, et al. Comorbidities and Charlson score in resected stage I nonsmall cell lung cancer. Eur Respir J 2005;26(3):480-486.

8. Bovelli D, Plataniotis G, Roila F. Cardiotoxicity of chemotherapeutic agents and radiotherapy-related heart disease: ESMO Clinical Practice Guidelines. Ann Oncol 2010;21(Suppl 5):v277-v282.

9. Lakoski SG, Eves ND, Douglas PS, Jones LW. Exercise rehabilitation in patients with cancer. Nat Rev Clin Oncol 2012;9(5):288-296.

10. NSCLC Meta-analysis Collaborative Group. Preoperative chemotherapy for non-small-cell lung cancer: a systematic review and meta- analysis of individual participant data. Lancet 2014;383(9928):15611571.

11. Song WA, Zhou NK, Wang W, Chu XY, Liang CY, Tian XD, et al. Survival benefit of neoadjuvant chemotherapy in non-small cell lung cancer: an updated meta-analysis of 13 randomized control trials. J Thorac Oncol 2010;5(4):510-516.

12. Burdett S, Stewart LA, Rydzewska L. A systematic review and meta-analysis of the literature: chemotherapy and surgery versus surgery alone in non-small cell lung cancer. J Thorac Oncol 2006; 1(7):611-621.

13. Lakoski SG, Barlow CE, Koelwyn GJ, Hornsby WE, Hernandez J, Defina LF, et al. The influence of adjuvant therapy on cardiorespiratory fitness in early-stage breast cancer seven years after diagnosis: the Cooper Center Longitudinal Study. Breast Cancer Res Treat 2013;138(3):909-916.

14. Bridevaux PO. Lung cancer rehabilitation study (LCRS). https:// clinicaltrials.gov/ct2/show/NCT01258478. Accessed January 20, 2016.

15. Edge S, Byrd D, Compton C, Fritz A, Greene F, Trotti A (editors). AJCC cancer staging manual, 7th edition: New York: Springer; 2010: 253.

16. Ramnath N, Dilling TJ, Harris LJ, Kim AW, Michaud GC, Balekian AA, et al. Treatment of stage III non-small cell lung cancer: diagnosis and management of lung cancer, 3rd ed: American College of Chest Physicians evidence-based clinical practice guidelines. Chest 2013;143(5 Suppl):e314S-e340S.

17. Vansteenkiste J, De Ruysscher D, Eberhardt WE, Lim E, Senan S, Felip E, et al. Early and locally advanced non-small-cell lung cancer (NSCLC): ESMO Clinical Practice Guidelines for diagnosis, treatment and follow-up. Ann Oncol. 2013;24(Suppl 6):vi89-vi98.

18. Miller MR, Hankinson J, Brusasco V, Burgos F, Casaburi R, Coates A, et al. Standardisation of spirometry. Eur Respir J 2005;26(2):319338.

19. Macintyre N, Crapo RO, Viegi G, Johnson DC, van der Grinten CP, Brusasco V, et al. Standardisation of the single-breath determination of carbon monoxide uptake in the lung. Eur Respir J 2005;26(4): 720-735.

20. American Thoracic Society, American College of Chest Physicians. ATS/ACCP Statement on cardiopulmonary exercise testing. Am J Respir Crit Care Med 2003;167(2):211-277.

21. Schmid A, Schilter D, Fengels I, Chhajed PN, Strobel W, Tamm M, Brutsche MH. Design and validation of an interpretative strategy for cardiopulmonary exercise tests. Respirology 2007;12(6):916-923.

22. Wasserman K, Hansen JE, Sue DY, Stringer WW, Sietsema KE, Sun XG, Whipp BJ. Principles of exercise testing and interpretation: including pathophysiology and clinical applications, 5th edition: Philadelphia: Lippincott Williams \& Wilkins; 2011:535.

23. Farkhooy A, Janson C, Arnardóttir RH, Malinovschi A, Emtner M, Hedenström H. Impaired carbon monoxide diffusing capacity is the strongest predictor of exercise intolerance in COPD. COPD 2013; 10(2):180-185.

24. Kreuter M, Vansteenkiste J, Herth FJ, Fischer JR, Eberhardt W, Zuna I, et al. Impact and safety of adjuvant chemotherapy on pulmonary function in early stage non-small cell lung cancer. Respiration 2013;87(3):204-210.

25. Rivera MP, Detterbeck FC, Socinski MA, Moore DT, Edelman MJ, Jahan TM, et al. Impact of preoperative chemotherapy on pulmonary function tests in resectable early-stage non-small cell lung cancer. Chest 2009;135(6):1588-1595.

26. Leo F, Solli P, Spaggiari L, Veronesi G, de Braud F, Leon ME, Pastorino U. Respiratory function changes after chemotherapy: an additional risk for postoperative respiratory complications? Ann Thorac Surg 2004;77(1):260-265, discussion 265. 


\section{Peak $\dot{\mathrm{O}}_{\mathrm{O}_{2}}$ Uptake in Lung Cancer Subjects Receiving Chemotherapy}

27. Takeda S, Funakoshi Y, Kadota Y, Koma M, Maeda H, Kawamura S, Matsubara Y. Fall in diffusing capacity associated with induction therapy for lung cancer: a predictor of postoperative complication? Ann Thorac Surg 2006;82(1):232-236.

28. Barnett SA, Rusch VW, Zheng J, Park BJ, Rizk NP, Plourde G, et al. Contemporary results of surgical resection of non-small cell lung cancer after induction therapy: a review of 549 consecutive cases. J Thorac Oncol 2011;6(9):1530-1536.

29. Ekblom B, Goldbarg AN, Gullbring B. Response to exercise after blood loss and reinfusion. J Appl Physiol 1972;33(2):175-180.

30. Grotto HZ. Anaemia of cancer: an overview of mechanisms involved in its pathogenesis. Med Oncol 2008;25(1):12-21.

31. Dolan LB, Gelmon K, Courneya KS, Mackey JR, Segal RJ, Lane K, et al. Hemoglobin and aerobic fitness changes with supervised exercise training in breast cancer patients receiving chemotherapy. Cancer Epidemiol Biomarkers Prev 2010;19(11):2826-2832.
32. Thakur A, Witteles RM. Cancer therapy-induced left ventricular dysfunction: interventions and prognosis. J Card Fail 2014;20(3):155158

33. Ekholm EM, Salminen EK, Huikuri HV, Jalonen J, Antila KJ, Salmi TA, Rantanen VT. Impairment of heart rate variability during paclitaxel therapy. Cancer 2000;88(9):2149-2153.

34. Stefanelli F, Meoli I, Cobuccio R, Curcio C, Amore D, Casazza D, et al. High-intensity training and cardiopulmonary exercise testing in patients with chronic obstructive pulmonary disease and non-smallcell lung cancer undergoing lobectomy. Eur J Cardiothorac Surg 2013;44(4):e260-e265.

35. Morano MT, Araújo AS, Nascimento FB, da Silva GF, Mesquita R, Pinto JS, et al. Preoperative pulmonary rehabilitation versus chest physical therapy in patients undergoing lung cancer resection: a pilot randomized controlled trial. Arch Phys Med Rehabil 2013;94(1):5358 . 